\title{
Research and Practice on the Cultivation of Innovative Talents among Internet of Things Students Based on New Engineering Mechanism
}

\author{
Qin Baoling ${ }^{1}$; Jiang Chun ${ }^{2}$ \\ ${ }^{1}$ College of Electronic Information Engineering, Foshan University \\ Guangdong Foshan 52800, China \\ E-mail: 2978879663@qq.com \\ ${ }^{2}$ Yunfu Ho.1 High School, Guangdong Yunfu 527300, China \\ E-mail: iawdjich@126.com
}

\begin{abstract}
At present, the concept of "New Engineering" advocated by the National Education Department aims at making up for the serious lag and inadequacy in the current college engineering education. At the same time, it is also a demand for engineering and technological innovation talents in terms of the society, the economy and national innovation development. Therefore, college engineering education must be reformed to cultivate more and more outstanding innovative talents. The authors combine the characteristics of Internet of Things (IoT) engineering and propose an innovative teaching model. The paper explores the relationship between teaching and learning from the nature of teaching. Driven by maximizing the benefits of teachers and students, a model of cultivating innovative talents has been activated and a fundamental reform in teaching and learning has been achieved by means of implementing competition projects and establishing an ecosystem platform for innovative talents. Practice has proved that the model is very effective, providing theoretical assistance and case support for the "New Engineering" innovative talent training model.
\end{abstract}

Keywords-New engineering; Internet of Things; Innovative talents; Architecture

\section{INTRODUCTION}

Firstly, with the continuous emergence of new technologies, the demand for talents in the society is constantly changing. One of the strange phenomenon of college graduates is that after graduation, many of them can't find jobs. Secondly, students can find job with professional counterparts. However, as the curriculum is unreasonable, what students learn is impractical and outdated; thirdly, students lack manipulative ability and innovative thinking. On February 18th, 2017, the Ministry of Education held a conference on advanced engineering at Fudan University in Shanghai and put forward the concept of "New Engineering", namely "Fudan Consensus". Major strategies including National innovation-driven development, "The Belt and Road Initiative", "Made in China 2025", "Internet+" become symbols of new economic development as new technologies, new formats, new models, and new industries, which raises a higher demand for engineers and technicians. As a result, we need to accelerate the reform and innovation of engineering education [1]. At present, the most urgent task in colleges and universities is to update the curriculum system. With a basis on the philosophy of national new engineering education and a need of combining the development of new technologies and their applications, we build an innovation talent cultivation system to open up students' innovative thinking, and to cultivate students' innovation and entrepreneurship. In this system, we increase practice, and emphasize and guide students to participate in project research and competitions. In this way, the philosophy of schooling can meet the today's requirements and keep up to date. Moreover, students can be recognized by enterprises and institutions, or many of them can't find a job after graduation.

Under the new engineering mechanism, IoT engineering involves a wide range of courses, including new technologies such as hardware and software. With the advancement, improvement of science and technology, and the continuous emergence and application of new technologies, students whose major is IoT engineering must have the ability of innovation and starting up business besides the solid basic knowledge. Therefore, curriculum design and teaching must be impractical and prospective, and so is the practise platform.

\section{THE CONSTRUCTION OF A NEW TEACHING QUALITY} SYSTEM FOR INTERNET OF THINGS COURSES UNDER THE NEW ENGINEERING SYSTEM

Constructing a new teaching quality system is a must for IoT engineering curriculum reform to adapt to the new engineering mechanism. It is also a major strategy for the national higher education curriculum reform [2]. With the rapid development of various new information and new technologies, IT talents are put forward with higher requirements in the society. Therefore, we need to reform the current old teaching model, and create new models of teaching quality, as the teaching quality in higher education is essential. 


\section{A. Reforming the IoT Engineering Professional Curriculum System}

The system of reform courses is a systematic project, from the management to each single teacher. We must adapt to the schooling concept of the new engineering. Aiming at comprehensively improving the students' innovative ability, we set up curriculum reform groups, in which everyone participates and takes responsibility. We make changes on the traditional curriculum design which lays emphasis on theory teaching instead of practise. The current courses not only pay attention to basic knowledge, but also combines new concepts and new technology. We also remove the similar courses and drop the impractical or outdated theory and technology courses. Meanwhile we advocate that the first-line teachers prepare the teaching materials for the new technology theory and practical teaching and apply these materials in teaching. The theory and practice courses will be in charge by the same teacher. We also update devices in the practice curriculum, guide students with knowledge modules or projects and cultivate students' innovative thinking and practical ability. At the same time, students are required to summarize the practice process and teachers are allowed to carry out the theory and practice teaching of elective courses on competition projects. In short, we have reformed curriculum settings, teaching materials, teaching content and practice.

\section{B. Constructing a New Teaching Quality System for Internet of Things Courses}

The new curriculum teaching quality system mainly includes the construction of teaching staff, innovative teaching models, and innovative practice bases, etc. With the guidance of competition projects, the teaching quality is improved through innovative teaching models. Consequently, students can consciously master new theories and new technologies while improving their innovation and practical ability.

1) Strengthening the building of teaching team and ensuring the smooth implementation of new teaching quality

The building of the teaching team is an important part of the teaching quality of colleges and universities. It is a key project which involves whether the relevant majors of the new engineering can be successfully carried out. Teachers are the primary resources for school education, and they are responsible for developing the country's future talents. They are also the indispensable and primary factor in promoting education equity, improving the quality of education, and building up as well as keeping the brand of colleges and universities. The teaching team building is fundamental to universities and colleges [3]. As a result, we need to consider and understand the importance of teacher's functions from a strategic and comprehensive perspective, and pay attention to the teachers' interests which are the most concerned, direct, and realistic. Such examples are: how to allocate the salary; how to reward people who have done more work; how to define the implicit workload; how to quantify work of significance and breakthrough; how to balance and quantify teaching and research, and how to show fairness, etc. These issues must be devised and improved at the school level. At present, most schools implement performance-based salary reform, which contains advantages but also many disadvantages. For instance, salary is cut to improve performance, which they spend money evaluating themselves; at the same school, of different secondary colleges, teachers who have basically the same job title and workload have great differences in their income; in addition, management group and experimental group are better than teachers' group, because the pressure on teachers is large and most of teachers' income are below the average level, which decreases the enthusiasm of most teachers. To sum up, when designing the system, the school must focus on the interests of teachers as a whole and find out the breakthroughs and focus of the building of the teaching team. Also, the school needs to adhere to an open and transparent principle and prioritize the interests of teachers. Then, the school can grasp the fundamentals of teaching team and create an outstanding talent ecosystem. It can introduce more talented people and stabilize their work, promote the benefits of three parties (schools, teachers, students), and guarantee the smooth implementation of newtype teaching quality.

2) Consolidating basic teaching on major and cultivating students' interests and practical application ability

IoT engineering major is a new engineering major with high level of comprehensiveness and technology. Most courses teachers have just received their $\mathrm{PhD}$ degree. They have a good command of knowledge. Yet, their teaching experience seems to be insufficient. The main manifestations are as follows: they teach the class in general without focus points or had points; they only read out the text in the PPT; they teach the class so flatly that students are not interested in listening; they simply explain the theory according to the text and do not give a multidimensional explanation.

The new teachers are the hope of the school. They are all doctoral graduates and have mastered the theory. However, they lack the teaching experience and practical experience. Therefore, the school must improve the cultivation of new teachers' teaching ability and practical ability, organize new teachers into teams, and focus on basic major courses teaching. Firstly, teachers need be familiar with the basic knowledge of the professional knowledge system. Secondly, when giving classes, teachers should explain the basic concepts, theories and principles with straightaway language. Thirdly, they also ought to explain the theory in a multidimensional interpretation and they should turn the abstract and deep concepts into small and easy ideas. With the mentioned means, students learn actively, not passively. Also, after teachers help students change their learning approaches, students become motivated to learn and interested in learning, improving their own application ability.

3) Attending cutting-edge technical lectures to improve students' mastery of new technology

Apart from teaching basic knowledge, we should focus on broadening students' knowledge and attend more cutting-edge technical lectures. This is because IoT engineering is combined with new technology. As new technology is advancing with each passing day, mastering the cutting-edge technologies means seizing the future. Thus, we need to strengthen contracts with scientific research institutes and related high-tech enterprises. We can invite the scientific 
research bigwigs to give regular lectures at school. We can even invite scientific researchers from foreign universities or enterprises for lectures so that we can broaden students' knowledge structure, improve their mastery of new technologies and cultivate students' innovative ability.

4) Opening Experiment Engineering Center to allow students to make projects and carry out experiments independently

The IoT engineering major involves more practical courses, because we enhance students' understanding of the professional knowledge and cultivate their application ability mainly through practice. At the same time, the school has a student academic fund project and college students innovation and entrepreneurship project each year. These two platforms provide students with opportunities for innovation training. Students can carry out project research according to their own situation. Also, the school's experimental engineering center is open to students all day, which meets the students' needs of various practices. Besides, the school encourages students to participate in teachers' projects, in which students can master research methods and techniques, improve their innovative entrepreneurial thinking and ability. Still, we strengthen cooperation with enterprises, establish students' practice bases, cultivate innovative talents for enterprises, and promote the development of industry-academic-research [4].

\section{CONSTRUCTION AND ANALYSIS OF INNOVATIVE TALENTS' ECOSYSTEM PLATFORM FOR IOT ENGINEERING MAJORS UNDER THE NEW ENGINEERING MECHANISM}

The construction of innovative talent ecosystem platform includes goals, principles, mechanisms, architecture, operation and maintenance, etc. It is the management platform of entrepreneurial innovative talents for IOT engineering majors and it is also the spiritual home for students' innovation and entrepreneurship. Students put forward and discuss their ideas in the platform, where students can gain innovative inspiration. Students can also communicate with teachers, discuss related issues, and apply for participation in the teachers' project in the platform. Such a platform can promote students' communication. Senior students help junior ones with their study and projects. Positive cycle development and innovative talent ecosystems are formed, and all of these have significant contributions to the society, school and students.

\section{A. Aims, principles and mechanism of the system platform construction}

\section{1) Aims}

The aim of the platform construction is for courses teachers and students who have different majors, but it still puts close attention to IoT students. The platform is a place where IoT students carry out scientific and technological innovation activities. With the platform, we create an outstanding environment for learning and scientific research, cultivate students' moralities such as overcoming the difficulties of scientific research. We also build up a base for students' innovation and entrepreneurship development to create more job opportunities for graduating students.

\section{2) Principles}

The principle of platform construction is to put emphasis on students' projects with teachers' assistance. During projects evaluation, we insist on prioritizing innovation, and insist principles of fairness and reasonableness. We improve students' scientific research quality, and stretch students' innovative mind.

\section{3) Mechanism}

The platform operation mechanism adopts the student's independent building and management mode. The platform is run by the IoT innovation team and it receives some financial support from the school, ensuring the operation of the system platform. Running the platform develops students' innovative management capabilities, which lays a foundation for future business start-up.

\section{B. Analysis of the system platform construction}

The innovative talent ecosystem mainly includes students, schools, enterprises, school-enterprise cooperation platforms, technology, etc [5]. The core is the cultivation of innovative talents. The school is mainly charge of the cultivation of students and the construction of majors and courses. Enterprises provide a practical base for innovative talents. The school-enterprise cooperation platform plays an important role in the transition and integration. Thus, it is important to build up a new talent ecosystem. The system platform construction is shown in Figure1. 


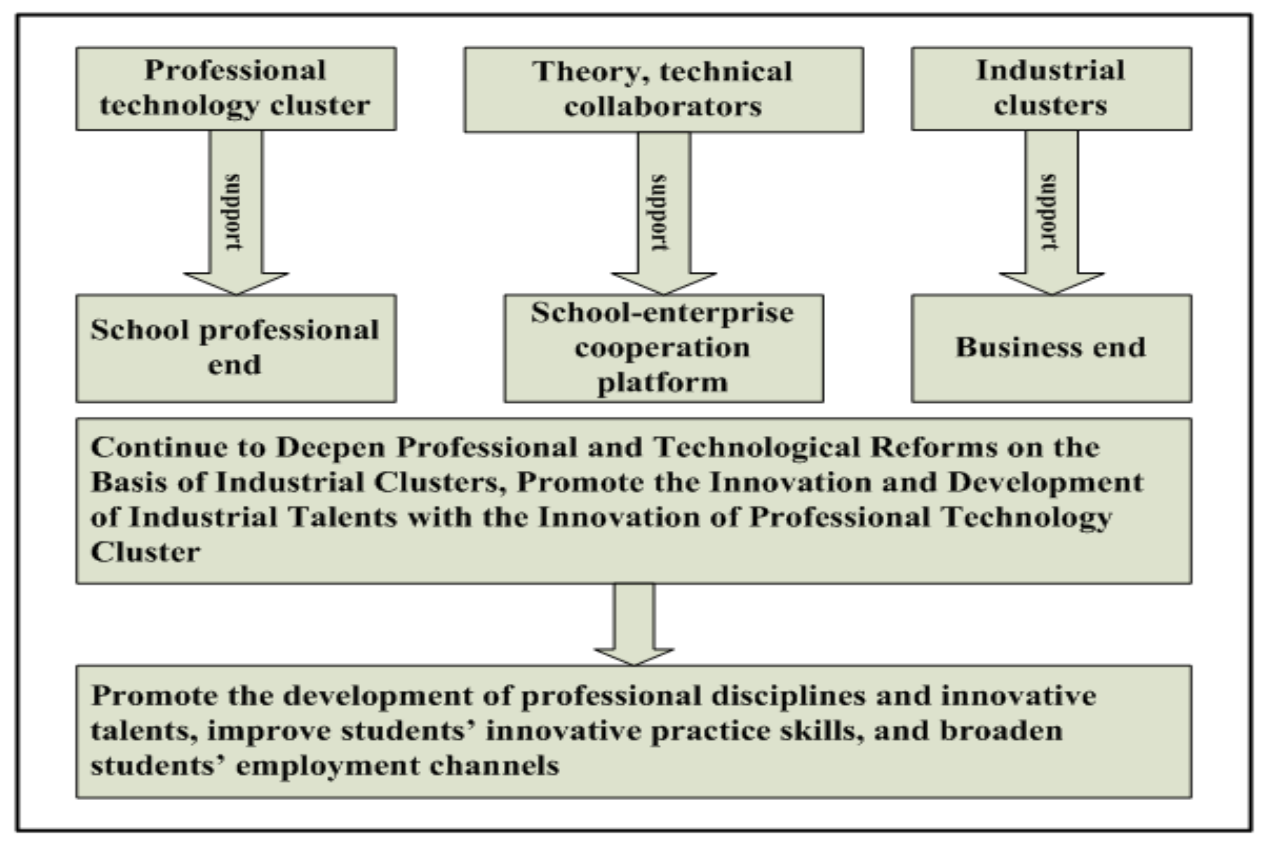

Fig. 1. Innovative Talents Ecosystem Platform

The ecosystem platform is an indispensable part of the training of innovative talents. It is a platform for students to develop their capabilities of self-management and selfadjustment. It is also effective for students to develop independent analytical thinking and problem-solving skills. Students are free to communicate academic ideas, analysis and their own opinions in the platform, where students are likely to have innovative inspiration. In research projects organized by senior and experienced students, we need to attract junior students with certain proportion. In this way, we can make students learn and help others at the same time and we can standardize this method. Therefore, the innovation research system platform can have a good ecological environment to ensure the implementation of innovative personnel training projects. This is the wanting outcome of the school's innovation and entrepreneurship practice and it is also the purpose of the "New Engineering" project.

\section{IMPLEMENTATION OF A NEW MODEL OF INNOVATIVE TALENTS CUltivation BASED ON COMPETITION PROJECTS}

Practice teaching is an important part of the cultivation of innovative talents. In the current new engineering mechanism, traditional practice teaching has fallen greatly behind and can not meet the needs of the development for the new era. Especially, it can not meet the requirements in the training of innovative talents for the Internet of Things project, because this new engineering major integrates many majors' theory and technology. The basic courses mainly include technology such as computer hardware and software, network engineering, communications and sensors [6]. In the current information era, new theories and new technologies are updating very rapidly. Therefore, we need to reform traditional practice teaching courses, and adopt new models of cultivating innovative talents based on competition projects to explore practical experience constantly. Moreover, we support students to participate in various innovation activities and encourage them to join in teacher research projects. In the implementation of the project, each student's specialty should be brought into play. At the same time, we establish a diversified and innovative teaching model to meet the needs of different groups of students, and to create a good talent ecosystem with innovative talents cultivation model. The model are carried out as follows.

(1)We take the competition project team as the unit, students as main body and teacher as guide. We carry out the project practice teaching and training, improve the students' initiative, and cultivate their innovative thinking.

(2)We adhere to the competition program as practiceoriented teaching and carry out a variety of training methods. Teachers set the scoring standards while students choose the projects by their own and team members can be combined depending on students' will. This can increase the chances of students with same interest staying together and discussing the problems. It can also create a good learning atmosphere for students, can cultivate students independent thinking as well as the capability of solving problems and can improve their innovate thinking.

(3)We encourage and guide students to actively participate in teachers' scientific research projects. Through the participation, students can learn methods, learn to communicate, and accumulate experience. This improves students' practical and communication skills, and cultivates their comprehensive quality.

(4)Based on the international engineering education certification, we unfold more cooperation with international engineering education, especially in the field of IoT engineering. We keep learning and absorbing foreign advanced engineering education concepts. At the same time, we must also combine the characteristics of local industries to run the International IoT engineering major with local features 
and to cultivate students' engineering innovation capabilities with an international perspective.

\section{PRACTICE ACCOMPLISHMENT}

In recent years, the training of innovative talents for the Internet of Things has made some accomplishment. Particularly gratifying, a large number of students have applied for innovation and entrepreneurship training projects and actively prepared various types of competition projects. Students participate in various national, provincial, municipal and school-level competitions under the guidance of teachers and they obtain prominent achievement. Competitions involve the Blue Bridge Cup, programming competition, Internet of Things design competition, and Mathematical Model Contest. In the past three years, the awards for the Internet of Things project have been:

(1) "Blue Bridge Cup":3 people gain National Second Prize and 5 gain Third Prize;

(2) "Mathematical Model Contest": 2 gain National Second Prize and 1 gain Provincial Third Prize;

(3) "Internet of Things Design Competition": 2 gain National Second Prize and 3 gain Third Prize;

(4) The "Program Design Competition":3 gain National Second Prize, 3 gain Third Prize, and 3 gain Provincial First Prize, 4 gain Second Prize;

(5) 2017 IOT Project 2 classes I organized and mentored a research team from IoT Engineering students of Class 2, Grade 2017. The team has gained 1 key academic project of the Innovation Academic Fund in 2018, and received a school grant of 8,000 yuan. College students innovation and entrepreneurship training program has won one national prize and one provincial prize. There are also many small projects that have won the Guangdong provincial prizes and school awards.

In addition, the school accelerates engineering education certification and strengthen international cooperation. In 2018, the School of Electronic Information Engineering has successfully obtained the international computer engineering education certification. It expands the space of school's international engineering education, and cultivates students' engineering innovation capabilities facing the world.

To sum up, those achievements have been benefited from teaching reform of innovative talent training. The reform not only develops students' innovative and entrepreneurial abilities, but also brings students training and benefits. The school has gained a lot of honors. At the same time, the quality of school running has been rapidly improved and has been recognized by the society, which is a win-win result.

\section{CONCLUSION}

The national "New Engineering" project education reform is a national educational strategy. The cultivation of innovative talents for the Internet of Things is facing severe challenges. The current problems include: teaching systems and its goals lag behind; the theoretical and practise teaching have been impractical; graduates' knowledge is outdated; graduates have shortcomings in engineering practise and innovation, etc. To solve all these problems, we need not only to introduce high-level professionals at the school level and solve the problem of teachers' salary, but also to implement a series of theoretical and practical teaching reforms to solve the most fundamental problems. We need to carry out the education reform with the innovative talent cultivation model. Furthermore, we need to bring up new methods or to remove the redundancies to ensure the effective implementation of teaching reforms. We also ensure double-basic (basic theory and basic technology) teaching, expand related professional theories and technical teaching, and seize every opportunity to hold cutting-edge technical lectures. Besides, we allow firstline teachers to select or edit textbooks depending on their needs, to remove old technology and add the new one. We shorten theoretical teaching time, and increase competition practice. As for students, we establish an academic professional ecosystem platform, increase students' academic communication and encourage them to participate more in various innovative and entrepreneurial activities. Under the new engineering mechanism, through teaching reform practice mentioned above, students with this major have greatly improved their capabilities in various aspects. In particular, we have won many awards in competitions and have higher rates of projects application in the past two years. This indicates that this reform is correct and the training mode is correct. In short, the ultimate goal is to cultivate students' innovative entrepreneurial thinking and ability.

\section{REFERENCES}

[1] "New Engineering" Fudan Consensus, Official Website of the Ministry of Education of the People's Republic of China - Higher Education Department, 2017-02-18. (In Chinese)

[2] Zhongguancun Software Park Homeland Magazine 2015 issue 1. (In Chinese)

[3] Baoling Qin. Research and Practice of Innovative Talents based on the Internet of Things Competition Mechanism. Advances in Social Science, Education and Humanities Research, volume 157[J]. November 2017: 190-193.

[4] Wang Feng, Mo Weijian.Research and Exploration on Enhancing Innovation Ability of Engineering Students Based on "Student Development"[J].College Education,2015(8):51-52. (In Chinese)

[5] Sheng Zhiqin. Exploration and Practice of Innovative Practice Ability Training System for Engineering Students in Research Universities[J]. Times Education, 2015(10):203-204. (In Chinese)

[6] Ye Jihua et al. Cultivation of students' innovative practical ability in the Internet of Things under the new engineering background [J]. Computer Education, 2018(3): P52-52. (In Chinese) 